\title{
Comparative Study on Microwave Absorbing Heating Characteristics and Microwave Deicing Performance of Airport Pavement Modified Concrete
}

He Huang ( $\square$ huangheafeu@163.com )

Air Force Engineering University

Jinyu Xu

Air Force Engineering University

Junliang Liu

Air Force Engineering University

Haowen Chen

Air Force Engineering University

\section{Research Article}

Keywords: airport pavement, absorbing materials, modified concrete, microwave deicing, heating efficiency

Posted Date: December 29th, 2021

DOI: https://doi.org/10.21203/rs.3.rs-1169115/v1

License: (c) (i) This work is licensed under a Creative Commons Attribution 4.0 International License. Read Full License 


\section{Abstract}

In this paper, the airport pavement concrete has been taken as the main research object, three kinds of absorbing materials, namely silicon carbide $(\mathrm{SiC})$, iron oxide $\left(\mathrm{Fe}_{3} \mathrm{O}_{4}\right)$ and graphite, have been respectively mixed into the concrete, and an open microwave testing system has been established. Based on this system, the basic mechanical properties, microwave heating characteristics, microwave deicing effect and its influencing factors of modified concrete are systematically studied. In addition, a comparative analysis of the influence mechanism of different absorbing materials on the strength and absorbing performance of pavement concrete is carried out. The results showed that the addition of $\mathrm{SiC}, \mathrm{Fe}_{3} \mathrm{O}_{4}$, and graphite could effectively enhance the microwave effect of pavement concrete, and the more the addition, the more obvious the improvement. Furthermore, under the same mixing amount, the degree of improvement of microwave deicing performance of each absorbing material from large to small is graphite, $\mathrm{Fe}_{3} \mathrm{O}_{4}, \mathrm{SiC}$. However, the addition of graphite will form several weak links in concrete, thereby reducing its overall mechanical properties. SiC can slightly improve the mechanical properties of pavement concrete, but it has no significant effect on the microwave absorption properties. With the addition of $\mathrm{Fe}_{3} \mathrm{O}_{4}$, the strength of concrete changes little, and the effect of microwave absorbing heating and microwave deicing is remarkable. In general, the comprehensive performance of microwave deicing of $\mathrm{Fe}_{3} \mathrm{O}_{4}$ modified concrete is optimal. This study has high scientific and practical significance, and can be widely applied to deicing projects on airports and high-grade highways.

\section{Introduction}

The cold areas in northern China are characterized by wide distribution, large precipitation in winter and long duration of low temperature. In some areas, severe snow and ice weather occurs frequently, which causes the airport pavement to be in a state of ice for a long time. The ice cover on the pavement surface will affect the friction coefficient and roughness to a great extent and significantly reduce the anti-skid performance, thus seriously endanger flight safety (Yang and Jin, 2002). Therefore, rapid and effective removal of pavement ice is a hot issue that needs to be solved urgently. Traditional deicing methods mainly include clearing method, melting method and restraining method (Zhou et al., 2014). Manual clearing method has high labor intensity and low working efficiency. Mechanical removal method has low ice removal rate and great damage to road surface (Yu, 2011). Chemical melting method has great harm to the pavement performance and ecological environment (Fu, 2010). Thermal melting method has high cost and low energy utilization (Wu, 2005). Although these methods can deice the road surface, they also expose the above defects at the same time. In order to make up for the problems existing in the traditional deicing method in practical operation, it is of economic value and practical significance to seek a deicing method with high energy utilization rate, less damage to the road surface and environmental protection.

Microwave heating technology, as rapid development of environmental protection technology, is widely used in the deicing of road surface in winter, and has achieved certain results. In recent years, many 
studies have been carried out on microwave deicing. Hopstock $(2003,2005)$ tested the improvement of microwave deicing efficiency of asphalt pavement by preparing microwave absorbing concrete with iron tunnel rock as aggregate. Wang (2010) established magnetron heating model, and calculated the electric field distribution of heating material by HFSS simulation. Wang et al. (2016) put forward a standard evaluation method of deicing, and from the perspective of rapid deicing and optimal economy, presented the best matching scheme for the new deicing design. Gao et al. (2017) explored the feasibility of using steel slag as the aggregate of microwave deicing asphalt mixture through experiments, and determined the most effective volume and particle size to partially replace the traditional aggregate. Gallego et al. (2013) used steel fiber as microwave absorbing component in asphalt concrete to increase the surface temperature of asphalt concrete, thereby improving deicing efficiency. Liu et al. (2018) improved the efficiency of concrete deicing by adding iron black into concrete. In the previous research on microwave deicing, most scholars focused on asphalt concrete. However, there are great differences in appearance and performance between cement concrete and asphalt concrete. Therefore, the existing conclusions are not suitable for microwave deicing of cement concrete pavement. In addition, most of the current scholars focus on a single microwave absorbing admixture, and there is a lack of cross-sectional comparative studies on a variety of different absorbing admixtures. Therefore, it is of great significance to test and study the static mechanical properties and the effect of microwave deicing of concrete mixed

with different absorbing materials, so as to seek the best absorbing materials, optimize the pavement mix design, and promote the microwave deicing technology.

In this paper, silicon carbide $(\mathrm{SiC})$, ferric oxide $\left(\mathrm{Fe}_{3} \mathrm{O}_{4}\right)$ and graphite have been respectively mixed into concrete to prepare three kinds of absorbing concrete. The microwave heating efficiency and deicing effect of concrete have been studied, and its compressive strength and flexural strength have been tested. Finally, the mechanism of different absorbing materials on concrete has been compared and analyzed. The research results provide a theoretical basis for further promotion of microwave deicing methods.

\section{Raw Materials And Specimen Preparation 2.1 Raw materials}

The cement used in this paper is 42.5 ordinary portland cement, and the water reducing agent is polycarboxylic acid water reducing agent with water reducing rate of $35 \%$. The specific mix proportion design is shown in Table 1 below.

In this paper, silicon carbide (SIC), iron oxide $\left(\mathrm{Fe}_{3} \mathrm{O}_{4}\right)$ and graphite are selected as the admixture of concrete (Fig. 1-Fig. 3). 
Table 1

Concrete reference mix ratio

\begin{tabular}{|lcccccccc|}
\hline $\begin{array}{l}\text { Material consumption per } \mathrm{m}^{3} \\
\text { of concrete }(\mathrm{kg})\end{array}$ & cement & water & large & $\begin{array}{l}\text { medium } \\
\text { stone } \\
\text { stone }\end{array}$ & $\begin{array}{l}\text { small } \\
\text { stone }\end{array}$ & sand & $\begin{array}{l}\text { water- } \\
\text { reducing } \\
\text { agent }\end{array}$ \\
\cline { 2 - 9 } & 330 & 135 & 575 & 575 & 287.5 & 562.5 & 3.63 \\
\hline
\end{tabular}

\subsection{Specimen preparation}

The size of the specimens was $150 \mathrm{~mm} \times 150 \mathrm{~mm} \times 150 \mathrm{~mm}$, and the amount of absorbing material was $0 \%, 5 \%, 10 \%$ and $15 \%$ respectively. In order to fully ensure the dispersion and uniformity of the distribution of the absorbing admixture in the concrete matrix and promote the formation of standardized specimen properties, this paper adopted PC mixing method. The specific steps were as follows: first, mixed coarse aggregate and fine aggregate for $60 \mathrm{~s}$, then poured in absorbing material and cement and continue to mix for $60 \mathrm{~s}$, and finally, added water and water reducing agent at the same time and mixed for $120 \mathrm{~s}$.

After the concrete mixing process was completed, the concrete was poured into the mold of $150 \mathrm{~mm} \times 150$ $\mathrm{mm} \times 150 \mathrm{~mm}$, and cured for 28 days under the standard state $\left(T=20 \pm 2^{\circ} \mathrm{C}\right.$, relative humidity $\left.>95 \%\right)$. Subsequently, the concrete specimens were made.

After curing, we carried out the frozen ice layer treatment on the concrete surface. The specific methods were as follows: Rigid PVC board was used to surround and fix the specimen to ensure that the upper edge of the board was parallel to and $20 \mathrm{~mm}$ higher than the concrete edge, and the whole specimen was wrapped with plastic cloth. Subsequently, water was poured over the concrete surface, so that the water level just reached the upper edge of the PVC board. Finally, the specimen was placed in the lowtemperature control cabinet for freezing. After the completion of freezing, the specimen could be prepared as shown in Fig. 4 below.

\section{Test Equipment And Test Method \\ 3.1 Test equipment}

The test equipment used for microwave deicing is an open microwave transmitting system designed independently. The equipment was composed of magnetron, water cooling device, height adjusting device, infrared temperature tester and external microwave control box, as shown in Fig. 5.

The temperature sensor was tested by WZP-128 thermal resistance with a temperature range of $-30^{\circ} \mathrm{C} \sim$ $250^{\circ} \mathrm{C}$. Its performance was stable and the temperature measurement accuracy could reach $0.1^{\circ} \mathrm{C}$. In the test, the MEACON multi-channel paperless recorder was used with a sampling accuracy of $0.1^{\circ} \mathrm{C}$ and a sampling period of $1 \mathrm{~s}$. It was able to collect and store the temperature data of 12 thermal resistances simultaneously.

\subsection{Test method}


(1) The compressive strength and flexural strength of $\mathrm{SiC}, \mathrm{Fe}_{3} \mathrm{O}_{4}$ and graphite concrete with different content are tested by electro-hydraulic servo test system, and the effects of three kinds of absorbing materials on the mechanical properties of specimens are compared and analyzed.

(2) The microwave source port is controlled to be $20 \mathrm{~mm}$ above the specimen surface, and the real-time temperature of the surface center point of three modified concrete specimens with different dosages is monitored and recorded every $4 \mathrm{~s}$.

(3) Simultaneously, the microwave source height of the device is adjusted to $20,30,50,70$, and $100 \mathrm{~mm}$. The real-time temperature at the center of the specimen is monitored and recorded every $4 \mathrm{~s}$.

(4) Subsequently, the height of the microwave source is fixed as $20 \mathrm{~mm}$. The ice state of SiC15, Fe15 and C15 ice covered modified concrete specimens in the process of deicing is investigated, and the comparative analysis of the deicing efficiency and effect is conducted.

\section{Test Results And Analysis}

Through tests, the compressive strength and flexural strength of $\mathrm{SiC}, \mathrm{Fe}_{3} \mathrm{O}_{4}$ and graphite modified concrete, as well as the real-time temperature during the microwave heating process are obtained. By comparing and analyzing the data and integrating the changing trends, the following quantitative results can be obtained.

\subsection{Influence of absorbing admixture on mechanical properties of concrete}

In this paper, with reference to the standard method for testing mechanical properties of ordinary concrete, an electro-hydraulic servo test system was used to conduct static compressive and flexural tests on ordinary concrete and wave-absorbing concrete specimens, with the loading rate of $0.5 \mathrm{MPa} / \mathrm{s}$. The compressive strength and flexural strength of $\mathrm{SiC}, \mathrm{Fe}_{3} \mathrm{O}_{4}$ and graphite concrete with different dosage were obtained respectively. Based on the test data, the effects of the three kinds of wave absorbing materials on the mechanical properties of concrete were compared and plotted as shown in Fig. 6.

It can be seen from the comparative analysis in Fig. 6 that the three kinds of absorbing admixtures have different effects on the basic mechanical properties of concrete. To some extent, SiC can improve the compressive strength and flexural strength of concrete, and the compressive strength and flexural strength increase with the increase of SiC content between $5 \%$ and $10 \%$, and reach the peak value when the content is $10 \%$. After the addition of $\mathrm{SiC}$, the two performance indexes are reduced. The compressive strength and flexural strength of $\mathrm{Fe}_{3} \mathrm{O}_{4}$ concrete will decrease with the increase of $\mathrm{Fe}_{3} \mathrm{O}_{4}$ content. The rate of decrease in the early stage is small, and the rate in the later stage increases. Compared with $\mathrm{Fe}_{3} \mathrm{O}_{4}$ concrete, the compressive strength and flexural strength of graphite concrete decrease more. When the content of graphite is $15 \%$, the compressive strength is only $58.1 \%$ of the PC compressive strength, and 
the flexural strength is only $81.9 \%$ of the PC flexural strength. The reduced concrete strength can still meet the road standard.

\subsection{Effect of SiC on microwave heating efficiency of concrete}

The temperature rise curve of the surface central point of concrete with different SiC content is shown in Fig. 7. It can be seen that (1) The real-time temperature curves all show a linear upward trend, and the incorporation of $\mathrm{SiC}$ will increase the temperature rise rate of concrete, so that the final temperature rise range increase as well. (2) When the height of the microwave source is fixed at $20 \mathrm{~mm}$ and the content of $\mathrm{SiC}$ is $5 \%, 10 \%$ and $15 \%$, the temperature rise range of the central point on the corresponding concrete surface is $58.3^{\circ} \mathrm{C}, 63.5^{\circ} \mathrm{C}$ and $70.8^{\circ} \mathrm{C}$, which are $112 \%, 109 \%$ and $110 \%$ of that of ordinary concrete respectively. The greater the content of SiC, the greater the temperature rise of concrete. Each $5 \%$ increase in the amount of $\mathrm{SiC}$ increases the temperature rise by $6.2^{\circ} \mathrm{C}, 5.2^{\circ} \mathrm{C}$, and $6.7^{\circ} \mathrm{C}$, respectively. The increase in the same amount of $\mathrm{SiC}$ on the microwave effect of concrete is basically the same.

In order to further analyze the influence of the addition of SiC on the microwave effect of concrete, the temperature rise amplitude of SiC5, SiC10 and SiC15 at different microwave source heights is tested, as shown in Fig. 8. It can be seen that (1) After adding SiC with different content, the change trend of temperature rise amplitude is the same as that of PC, which decreases with the increase of microwave source height. (2) The higher the content of SiC, the higher the temperature rise of concrete. (3) When the microwave source height reaches $30,50,70$, and $100 \mathrm{~mm}$, the temperature rise amplitude of SiC15 relative to $\mathrm{PC}$ is $19.8^{\circ} \mathrm{C}, 15.2^{\circ} \mathrm{C}, 13.6^{\circ} \mathrm{C}$, and $4.9^{\circ} \mathrm{C}$, respectively. The incorporation of $\mathrm{SiC}$ increases the temperature rise to a lesser extent. As the height of the microwave source increases, the temperature rise gradually decreases.

\subsection{Effect of $\mathrm{Fe}_{3} \mathrm{O}_{4}$ on microwave heating efficiency of concrete}

The temperature rise curve of the central point on the surface of Fe5, Fe10 and Fe15 specimens is shown in Fig. 9. It can be seen that (1) The surface temperature rise of concrete increases with the addition of $\mathrm{Fe}_{3} \mathrm{O}_{4}$. (2) At the same height of microwave source, the higher the content of $\mathrm{Fe}_{3} \mathrm{O}_{4}$, the greater the microwave effect of concrete. (3) The real-time temperature curve of ordinary concrete shows a linear upward trend. After incorporation of $\mathrm{Fe}_{3} \mathrm{O}_{4}$, the temperature rise rate gradually decreases with the increase of microwave action time, which is related to the temperature sensitivity of $\mathrm{Fe}_{3} \mathrm{O}_{4}$ microwave effect.

In order to further explore the influence of $\mathrm{Fe}_{3} \mathrm{O}_{4}$ on the microwave effect of concrete, the temperature rise amplitude at the central point of the specimen at different microwave source heights is measured, as shown in Fig. 10. It can be seen that (1) The temperature rise amplitude of concrete decreases with the increase of the microwave source height after adding different contents of $\mathrm{Fe}_{3} \mathrm{O}_{4}$. (2) When the 
microwave source height is fixed at $20 \mathrm{~mm}$, the temperature rise of $\mathrm{Fe} 15$ can reach $99.9^{\circ} \mathrm{C}$, while the temperature rise of $\mathrm{PC}$ is only $52.1^{\circ} \mathrm{C}$. The addition of $\mathrm{Fe}_{3} \mathrm{O}_{4}$ increases the temperature by $47.8^{\circ} \mathrm{C}$. The effect of the addition of $\mathrm{Fe}_{3} \mathrm{O}_{4}$ on the temperature of concrete gradually decreases with the height of the microwave source, and as the height increases, the decreasing amount gradually increases.

\subsection{Effect of graphite on microwave heating efficiency of concrete}

The temperature rise curve of the surface central point of concrete with different graphite content is shown in Fig. 11. It can be seen that (1) With the prolongation of microwave action time, the temperature rise curve of graphite concrete always shows a linear trend. (2) After graphite is added, the temperature rise of concrete in the microwave field increases significantly. When the graphite content is $5 \%, 10 \%$ and $15 \%$, the temperature rise is $78.1^{\circ} \mathrm{C}, 101^{\circ} \mathrm{C}$ and $130.1^{\circ} \mathrm{C}$, respectively, which is $149 \%, 193 \%$ and $249 \%$ of that of ordinary concrete.

In order to judge the improvement of the microwave effect of graphite on concrete more accurately, the temperature rise amplitude of $\mathrm{C} 5, \mathrm{C} 10$ and $\mathrm{C} 15$ at different microwave source heights is analyzed, as shown in Fig. 12. It can be seen that (1) When different amounts of graphite are added, the temperature rise amplitude of concrete decreases with the increase of the height of the microwave source, and the decrease rate is obvious. (2) When the microwave source height is $20 \mathrm{~mm}$, the temperature rise amplitude increases by about $25^{\circ} \mathrm{C}$ for every $5 \%$ increase of graphite content. The microwave thermal effect of concrete is greatly improved by adding graphite.

\subsection{Comparative analysis of deicing effect}

In order to further explore the influence of SiC admixture on the microwave deicing efficiency of concrete, tests on the surface ice state of SiC15 specimen under different microwave action times is carried out. The results are shown in Fig. 13. It can be seen that when the microwave action time is within the range of $0 \sim 70 \mathrm{~s}$, the ice layer above the SiC15 specimen always maintains the initial freezing state, and the thickness of ice does not change. When the microwave action time reaches $90 \mathrm{~s}$, the melting phenomenon starts to appear below the ice layer at the central point of the concrete surface. When the microwave is applied for $120 \mathrm{~s}$, the ice above the concrete central point has completely melted, and the surface melting area continues to increase. When the microwave action time reaches $160 \mathrm{~s}$, the melting area of the ice layer above the SiC15 specimen expands further.

In order to explore the effect of $\mathrm{Fe}_{3} \mathrm{O}_{4}$ on the efficiency of microwave deicing of concrete, the ice state of Fe15 specimen surface under different microwave action time is given, as shown in Fig. 14. It can be seen that when the microwave action time is in the range of 0-50s, the ice layer above the concrete is always frozen and has not changed. When the microwave is applied for $70 \mathrm{~s}$, the ice layer below the Fe15 central point melts, which is shortened by 20 s compared with the time when the SiC 15 specimen of sic begins to melt. When the microwave action time is $110 \mathrm{~s}$, the ice layer above the Fe 15 central point has completely melted, and the melting area on the surface of the specimen continues to increase. When the 
microwave action reaches $160 \mathrm{~s}$, the melting area on the concrete surface further expands, and at the same time, a considerable part of the ice layer has completely melted into water.

The ice state of $\mathrm{C} 15$ under different microwave time is given, as shown in Fig. 15. It can be seen that the ice layer above $\mathrm{C} 15$ is always frozen within 0-30 s of microwave action. When the microwave action is 50 $\mathrm{s}$, the ice layer below the concrete central point has melted. Then the melting area at the center of the ice layer gradually becomes larger, while the thickness of the ice layer above the melting area becomes thinner. When the microwave is applied for $90 \mathrm{~s}$, it can be seen that the central part of C15 specimen has completely melted, and the melting area of concrete surface continues to increase. When the microwave action reaches $130 \mathrm{~s}$, the area where the ice layer on the concrete surface completely melts continues to increase. However, the increasing range is not obvious, and the water under ice layer has leaked out from the periphery of the concrete. To sum up, it can be analyzed that at the same $15 \%$ content, the microwave deicing efficiency of three microwave absorbing materials on concrete in order from high to low is graphite, $\mathrm{Fe}_{3} \mathrm{O}_{4}$, $\mathrm{SiC}$.

\subsection{Mechanism analysis}

Different wave absorbing admixtures have different effects on concrete strength. SiC is a hexagonal crystal with a specific gravity between 3.20 and 3.25 , which has the advantages of stable chemical properties, high thermal conductivity and good wear resistance (Huang and Liu, 2009; Joshi et al., 2000). After mixing with concrete, due to its high hardness, it can improve the mechanical properties of weak links such as transition zone to some extent, so the mechanical properties of concrete have been improved. However, when the specimen is cured and formed in strength, the powdered $\mathrm{Fe}_{3} \mathrm{O}_{4}$ will not produce cohesive force, so the addition of $\mathrm{Fe}_{3} \mathrm{O}_{4}$ will not improve the mechanical properties of concrete. When a large amount of $\mathrm{Fe}_{3} \mathrm{O}_{4}$ is added, the cementation of cement will be weakened due to the dilution of $\mathrm{Fe}_{3} \mathrm{O}_{4}$, so the compressive strength and flexural strength will show a downward trend with the increase of the content. For graphite, the density is small, the pores are well developed and the surface area is large. After the specimen is formed and cured, due to the small density of graphite itself, it basically has no strength and will form many weak links in concrete. When subjected to external forces, these weak links are destroyed rapidly, which makes the concrete specimen lose strength. Therefore, the compressive and flexural strength of graphite concrete show a decreasing trend, and the decreasing amplitude of the strength increases with the increase of the graphite content.

The mechanism of improving the microwave heating efficiency of concrete is also different with different absorbing admixtures. SiC material itself has low resistivity and strong electrical conductivity. Under the action of microwave, SiC will be polarized by particles inside the concrete (Shen et al., 2007). The direction of the polarization vector is shifted by an angle from the electric field, thus producing a current in phase with the microwave field, which generates vortices in the concrete and in turn generates heat. After adding $\mathrm{Fe}_{3} \mathrm{O}_{4}$ into concrete, the relative positions of $\mathrm{Fe}^{3+}$ and $\mathrm{Fe}^{2+}$ in $\mathrm{Fe}_{3} \mathrm{O}_{4}$ make it highly magnetic. The magnetic moment of $\mathrm{Fe}_{3} \mathrm{O}_{4}$ is determined by the direction of the low-frequency alternating magnetic field under the influence of microwaves. Therefore, the molecules will rearrange and rotate rapidly under 
the influence of the magnetic field, thereby converting the microwave energy into heat. At the same time, due to the strong magnetism brought by $\mathrm{Fe}_{3} \mathrm{O}_{4}$, the magnetic induction intensity of concrete lags behind its own magnetic field intensity in the process of repeated magnetization, which will also convert the microwave energy into heat (Liu et al., 2007; Zhang, 2010). Graphite has excellent conductive properties and can form a whole or partial conductive network in concrete. Under the action of microwave, graphite concrete will cause heat loss because of the conduction current. Graphite particle size is small and the specific surface area is large. When irradiated by microwave, it is easy to produce multiple scattering and reflection of microwave, which can make the microwave lose rapidly after entering concrete and emit a large amount of heat (Duan et al., 2008; Jahanbakhsh et al., 2018; Meng et al., 2009).

\section{Conclusion}

In this paper, pavement concrete with three kinds of absorbing materials doped with silicon carbide (SiC), ferric oxide $\left(\mathrm{Fe}_{3} \mathrm{O}_{4}\right)$ and graphite has been taken as the research object. The basic mechanical properties, microwave heating characteristics and microwave deicing effect of pavement concrete after incorporating wave absorbing materials have been tested respectively, and the action mechanism of different wave absorbing materials on concrete have been compared and analyzed. The main conclusions are as follows.

(1) The addition of $\mathrm{SiC}, \mathrm{Fe}_{3} \mathrm{O}_{4}$, and graphite can effectively improve the microwave effect of concrete, and the more the amount is, the more obvious the microwave effect of concrete is. Under the same dosage, the improvement degree of the microwave deicing performance of each absorbing material on concrete is as follows: graphite, $\mathrm{Fe}_{3} \mathrm{O}_{4}$, $\mathrm{SiC}$.

(2) After adding $\mathrm{SiC}$ and graphite, the temperature rise curves of concrete show a linear upward trend, and the temperature rise rate is not affected by temperature. When $\mathrm{Fe}_{3} \mathrm{O}_{4}$ is added, the higher the temperature of concrete is, the lower the temperature rise rate is in the microwave field. When the temperature is greater than $40^{\circ} \mathrm{C}$, the temperature rise rate of concrete decreases rapidly, and the microwave effect of $\mathrm{Fe}_{3} \mathrm{O}_{4}$ is temperature-sensitive.

(3) The addition of $\mathrm{Fe}_{3} \mathrm{O}_{4}$ and graphite will reduce the compressive and flexural strength of concrete, and the influence of graphite is greater than that of $\mathrm{Fe}_{3} \mathrm{O}_{4}$. The addition of silicon carbide can increase the compressive and flexural strength of concrete by $5-10 \%$, and improve the basic mechanical properties of concrete to a certain extent.

(4) Through a comparative analysis of concrete strength and temperature rise amplitude, among the three kinds of absorbing materials, $\mathrm{SiC}$ can slightly improve the mechanical properties of concrete, but the improvement of microwave effect is relatively low. Graphite can increase the efficiency of microwave heating of concrete by $9 \%$, but the mechanical properties of concrete are greatly reduced. However, the addition of $\mathrm{Fe}_{3} \mathrm{O}_{4}$ has a small decrease in the strength of concrete, and the microwave effect on concrete 
can be increased by $192 \%$. The microwave heating effect and deicing effect are remarkable. Therefore, the $\mathrm{Fe}_{3} \mathrm{O}_{4}$ modified concrete has a better comprehensive performance.

Based on the above conclusions, this paper provides a certain theoretical basis and technical support for the microwave deicing technology of airport pavement, which is of high scientific significance and popularization value. In future studies, we will further study the interaction mechanism of various microwave absorbing materials and explore the optimal airport pavement modified concrete.

\section{References}

1. Duan, Y.P. et al. (2008) 'Absorbing properties of a-manganese dioxide/carbon black double-layer composites', Journal of PhySiCs D: Applied PhySiCs, 41(12): 395-403.

2. Fu, G.W. (2010) 'Study on the influence of snow melting agent on the performance of asphalt and asphalt mixture', Changsha University of Science \& Technology.

3. Gallego, J. et al.(2013) 'Heating asphalt mixtures with microwaves to promote self-healing', Construction and Building Materials, 42: 1-4.

4. Gao, J. et al. (2017) 'Utilization of steel slag as aggregate in asphalt mixtures for microwave deicing', Journal of Cleaner Production, 152:429-442.

5. Hopstock, D.M. (2003) 'Microwave-absorbing road construction and repair material', Final Report to NRRI on Idea Evaluation Subcontract.

6. Hopstock, D.M. (2005) 'Minnesota Taconite as a Microwave-Absorbing Road Aggregate Material for Deicing and Pothole Patching Applications Final Report', Applications Final Report.

7. Huang, Z.Y. and Liu, Q. (2009) 'Research on ultra-high strength and abrasion resistance concrete materials', Natural Science Journal of Xiangtan University, 31(1):92-97.

8. Jahanbakhsh, H. et al. (2018) 'Induction heating and healing of carbon black modified asphalt concrete under microwave radiation', Construction and Building Materials, 174: 656-666.

9. Joshi, R.P., Neudeck, P.G., and Fazi, C. (2000) 'Analysis of the temperature dependent thermal conductivity of silicon carbide for high temperature applications', Journal of Applied Physics, 88(1): 265-269.

10. Liu, J.L. et al. (2018) 'Study of microwave de-icing efficiency of concrete with various addition of iron black', Concrete, 346(08):36-39.

11. Liu, S.H., Liu, J.M. and Dong, X.K. (2007) 'Electromagnetic wave shielding and absorbing materials', Chemical industry press.

12. Meng, W. et al. (2009) 'Absorption properties of carbonyl-iron/carbon black double-layer microwave absorbers', Journal of Magnetism and Magnetic Materials, 321(20): 3442-3446.

13. Shen, Z.Q., Kang, Q., and Liu, L. (2007) 'Experimental study on electromagnetic shielding performance of sic/graphite concrete', Journal of Functional Materials, 38(A08): 3081-3083. 
14. Wang, C. et al.(2016) 'Numerical analysis on thermal characteristics and ice melting efficiency for microwave deicing vehicle', Modern Physics Letters B, 30(13):1650203.

15. Wang, R.B. (2010) 'Study on heating uniformity of microwave road de-icing equipment', University of Electronic Science and Technology of China.

16. Wu, H.Q. (2005) 'Research on the technology of melting snow and ice on road surface by heating cable', Beijing University of Technology.

17. Yang, X.D. and Jin, J.F. (2002) 'Development of ice adhesion theory and antifreeze technology', Journal of Changchun University of Science and Technology, 25(4): 17-19.

18. Yu, Y. X. (2011) 'Development and prospect of pavement active ice (snow) melting technology', Journal of Shanghai Jiao tong University, (S1):86-89.

19. Zhang, J.Y. (2010) 'Study on the characteristics of fly ash of high speed iron and its wave absorption of cement-based composites', Chongqing University.

20. Zhou, J.Z. et al. (2014) 'The research and summary of road deicing methods', Advanced Materials Research, 955: 1835-1839.

\section{Figures}

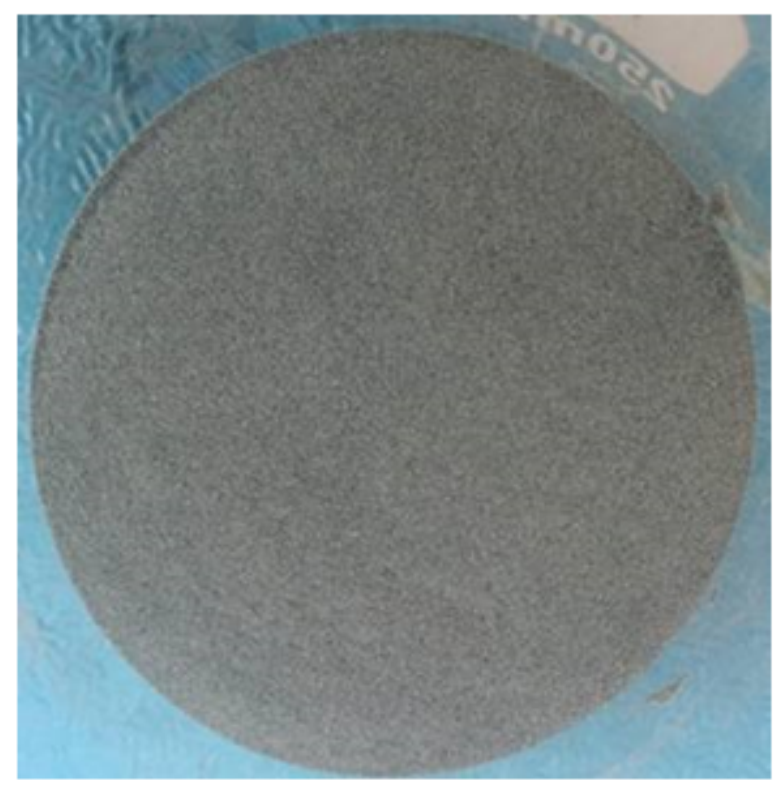

\section{Figure 1}

SiC 


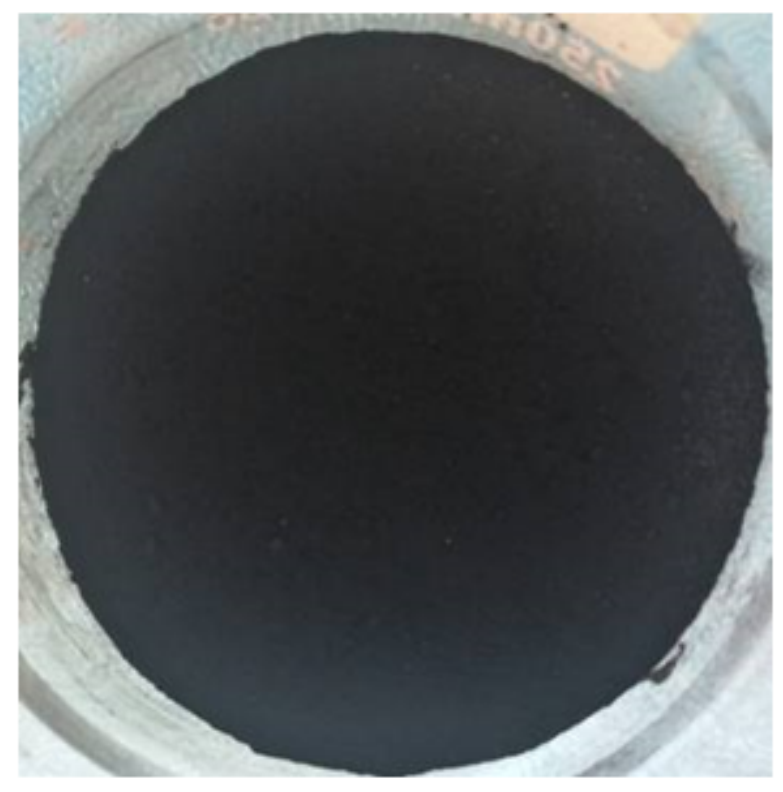

Figure 2

$\mathrm{Fe}_{3} \mathrm{O}_{4}$

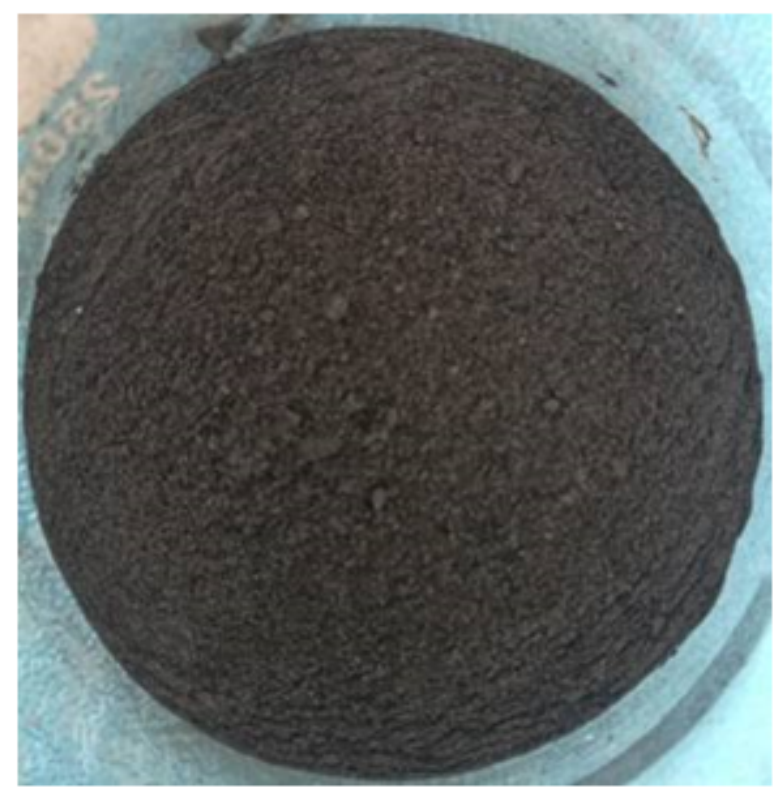

Figure 3

Graphite 


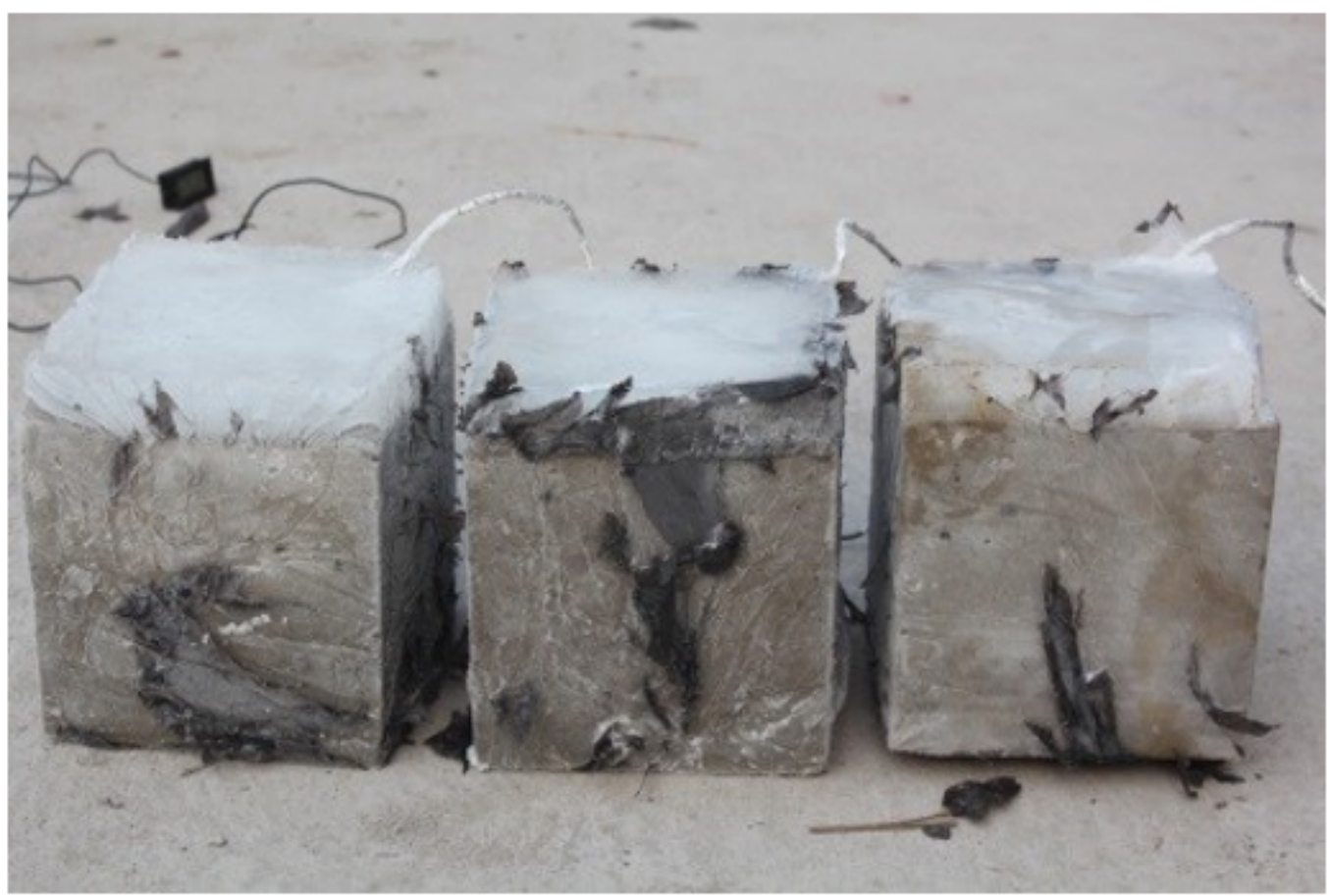

Figure 4

Concrete specimens of frozen ice 


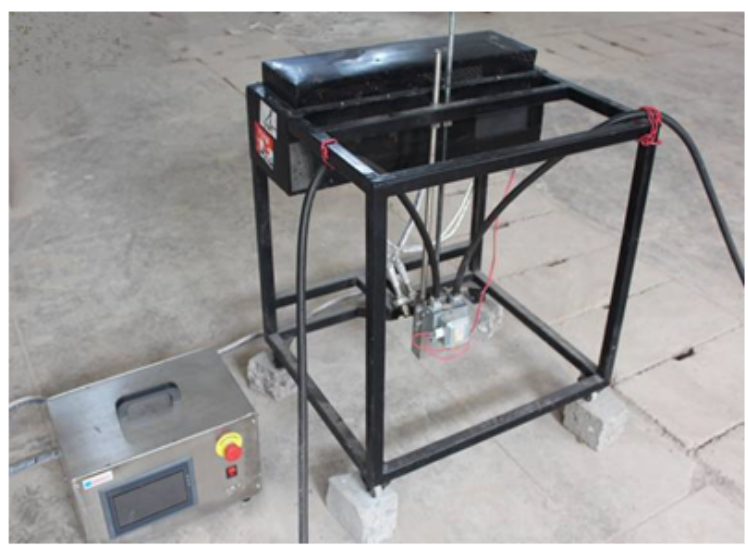

(a) Deicing main equipment

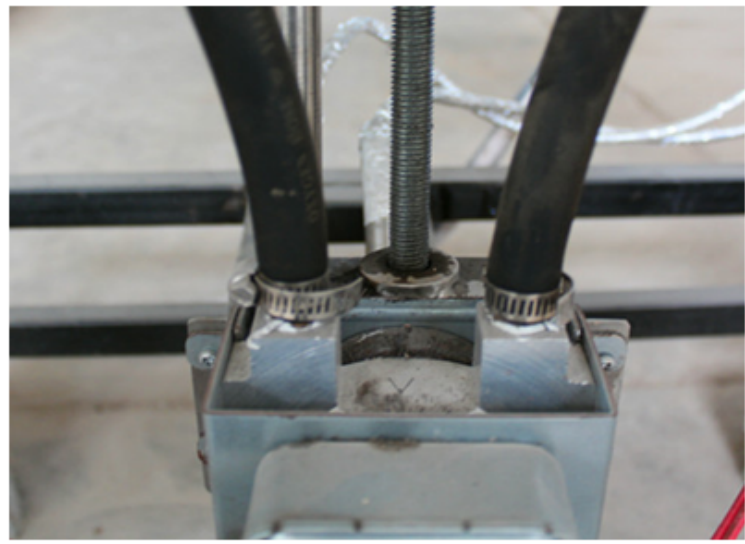

(c) Water cooling pipeline

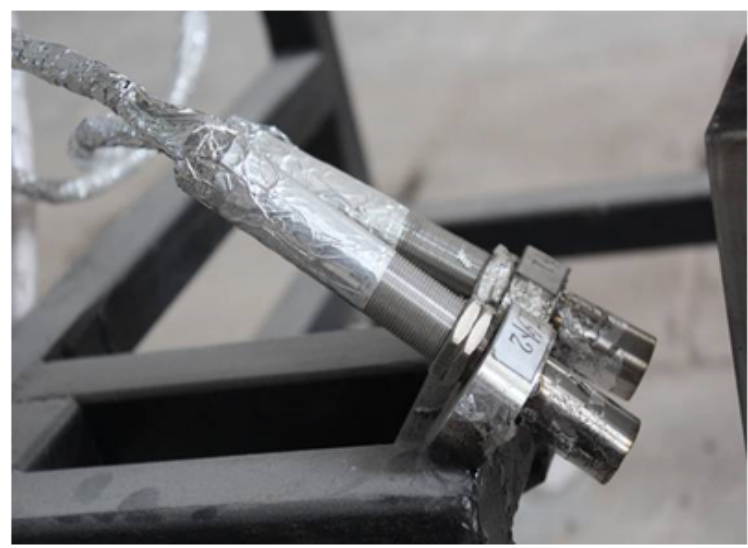

(e) Infrared thermometer

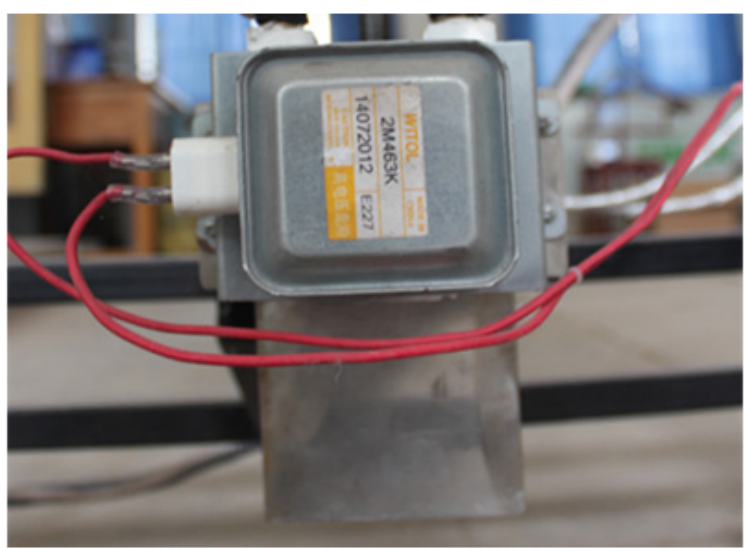

(b) Magnetron

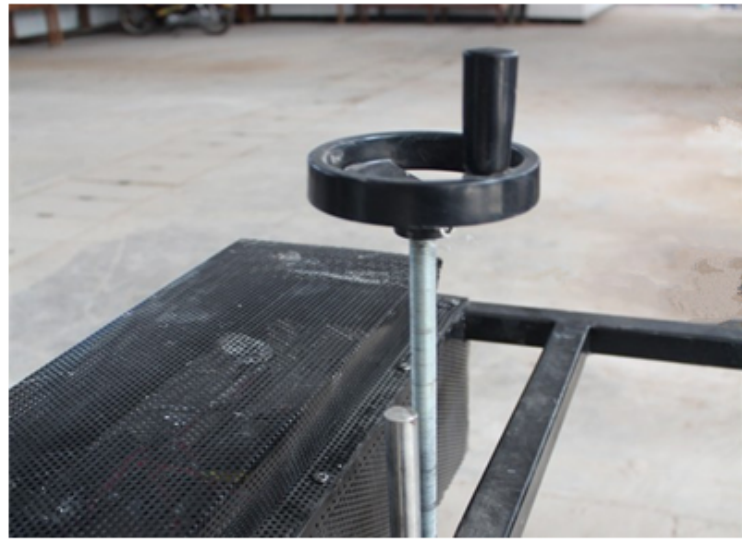

(d) Height control handle

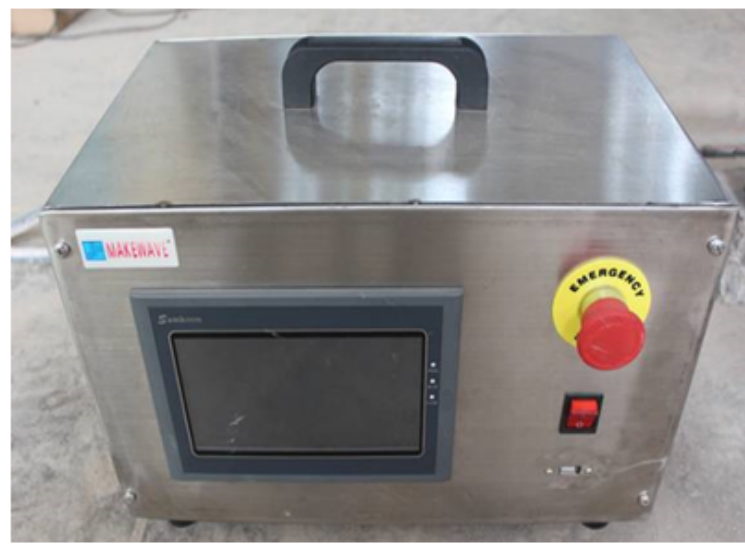

(f) Remote control box

Figure 5

Microwave deicing test equipment 


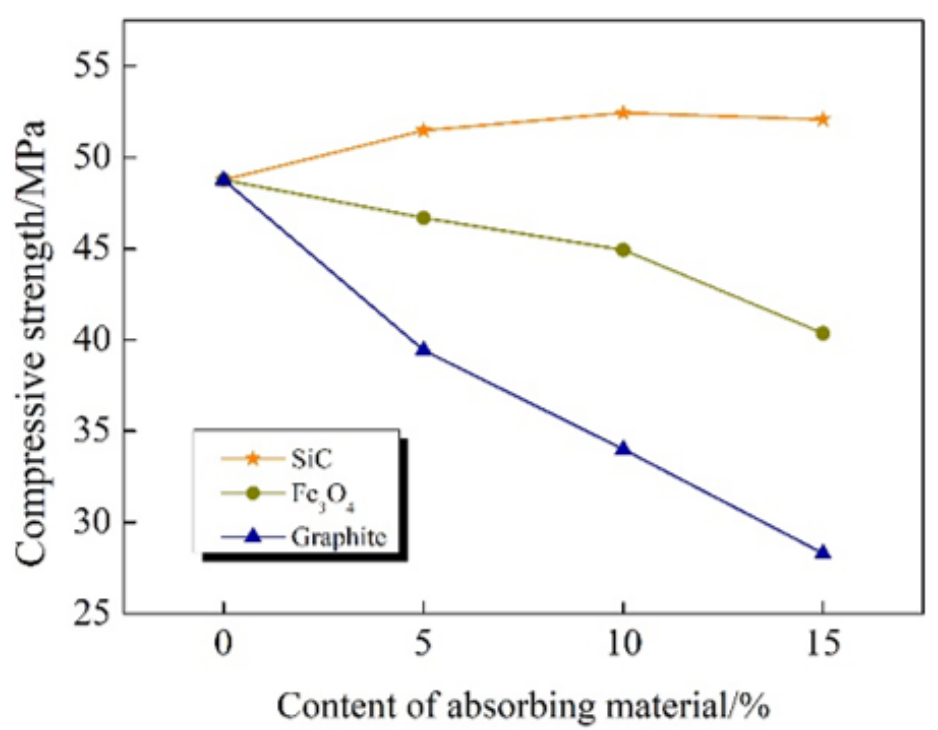

(a) Compressive strength

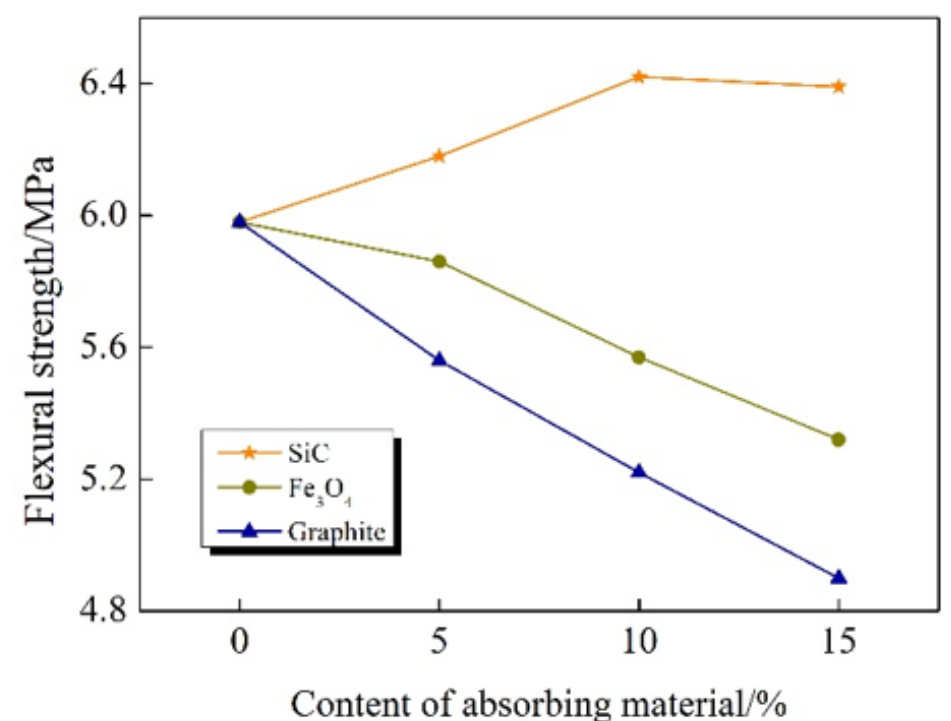

(b) Flexural strength

Figure 6

Effects of $\mathrm{SiC}, \mathrm{Fe}_{3} \mathrm{O}_{4}$ and graphite on the mechanical properties of concrete

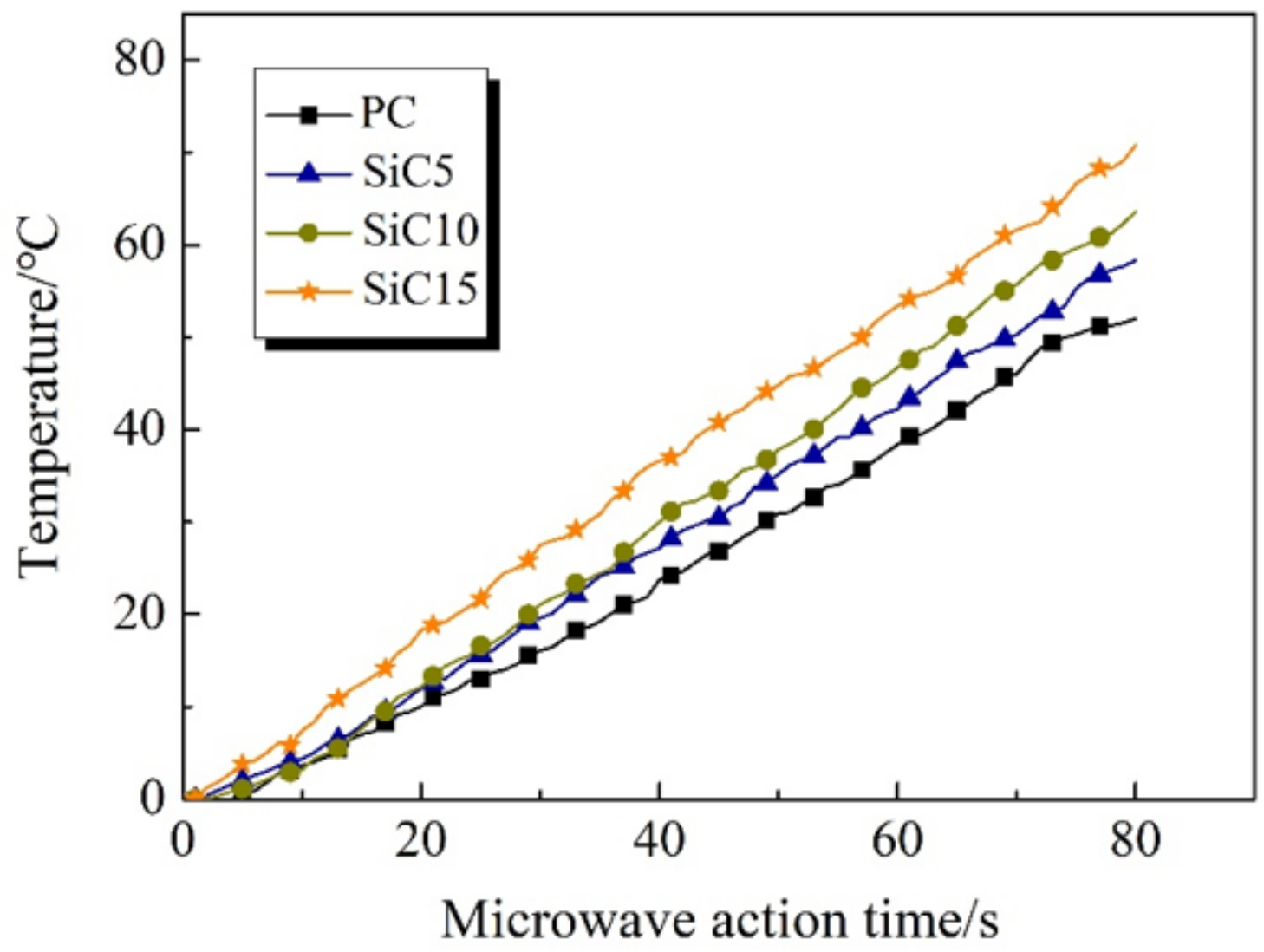

Figure 7

Real time temperature of SiC concrete 


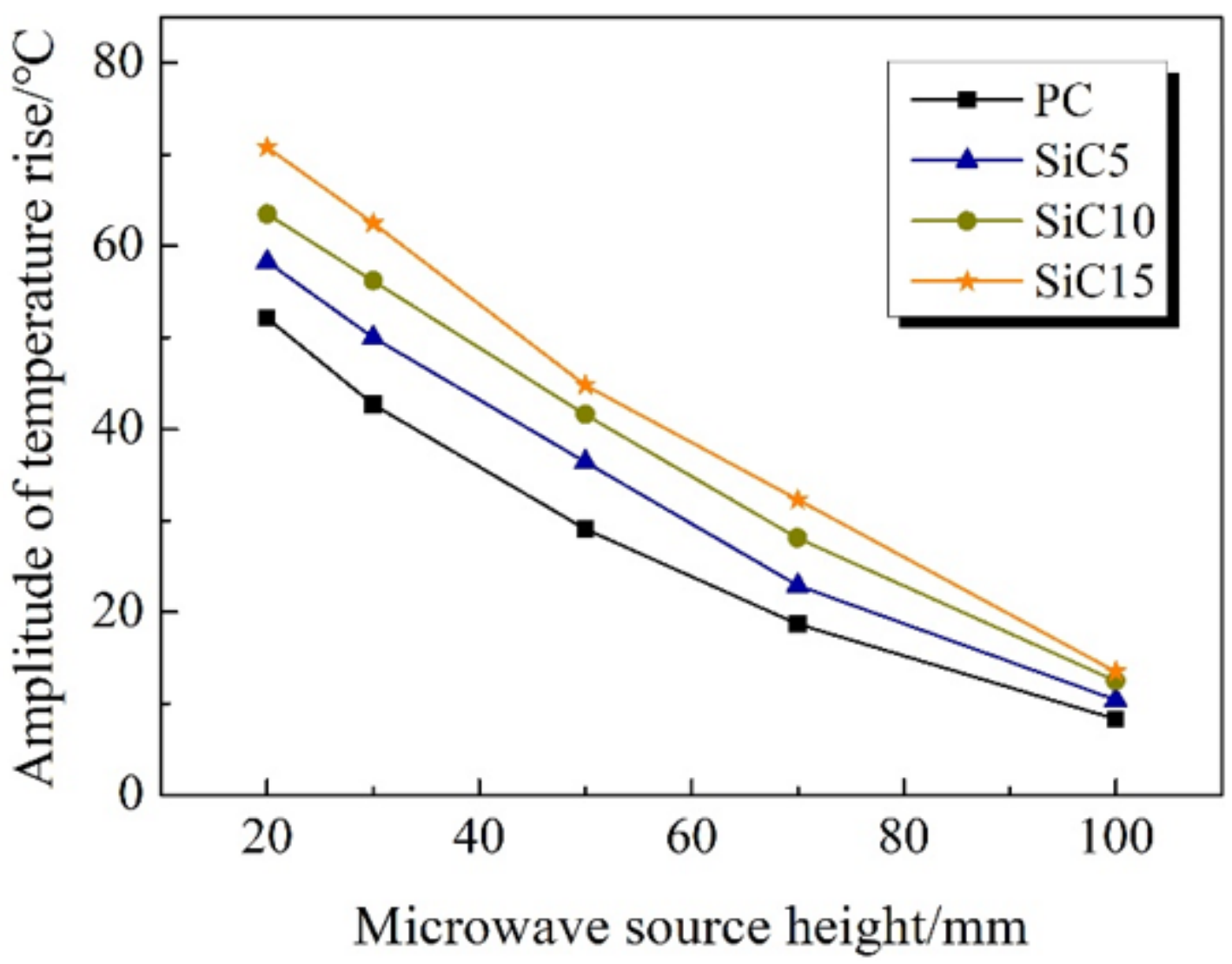

Figure 8

Amplitude of rising temperature of SiC concrete 


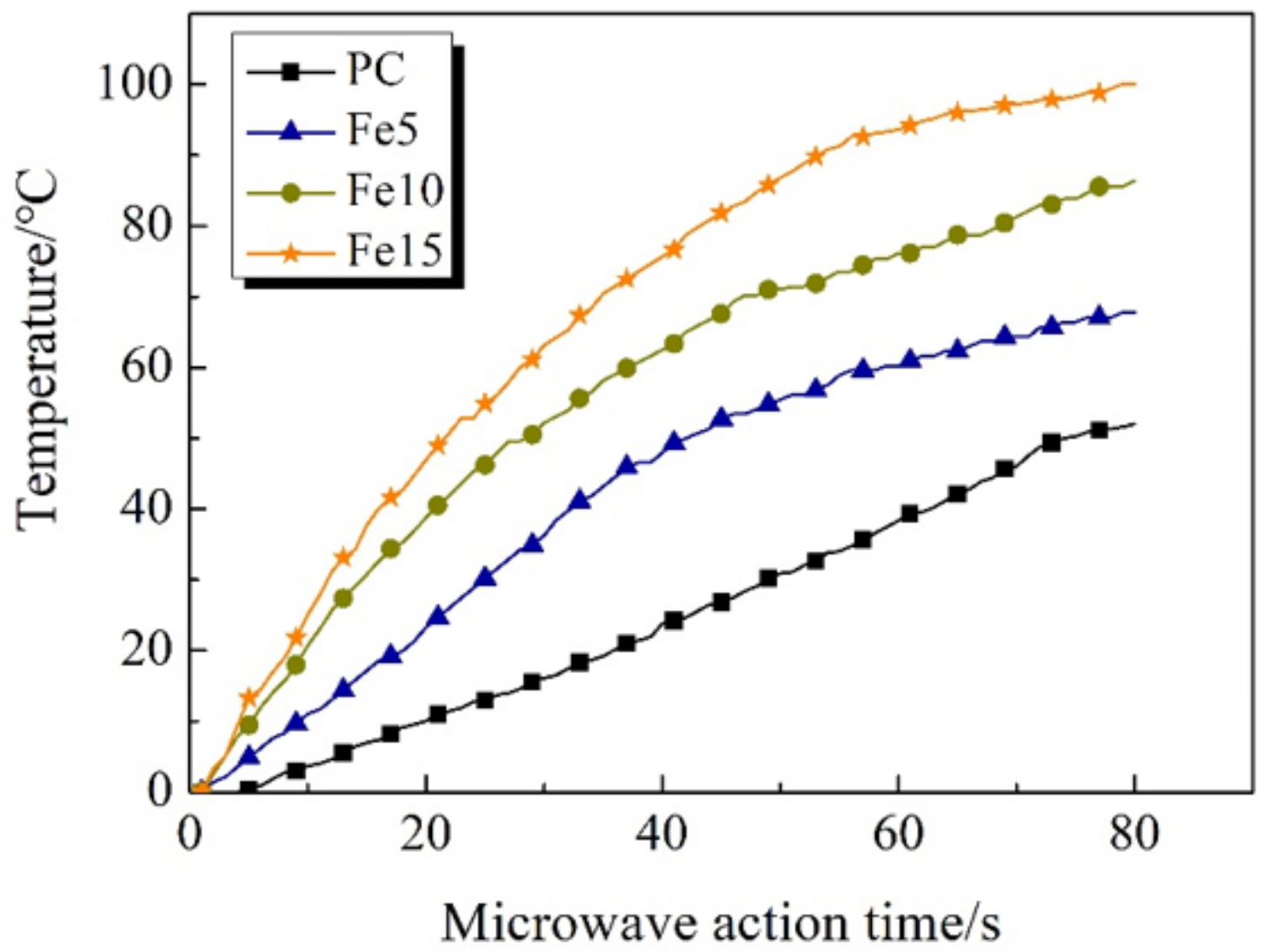

Figure 9

Real time temperature of $\mathrm{Fe}_{3} \mathrm{O}_{4}$ concrete 


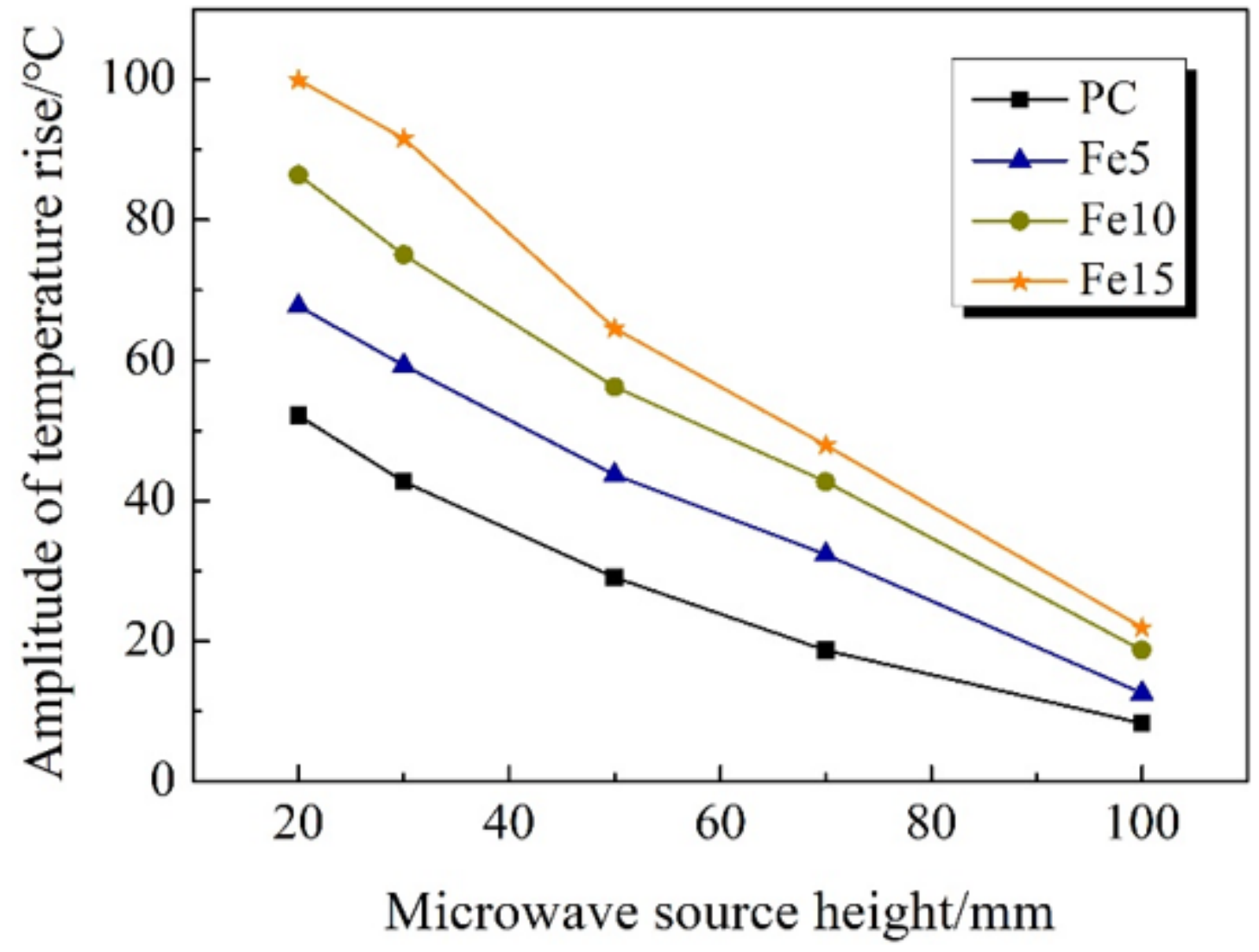

Figure 10

Amplitude of rising temperature of $\mathrm{Fe}_{3} \mathrm{O}_{4}$ concrete 


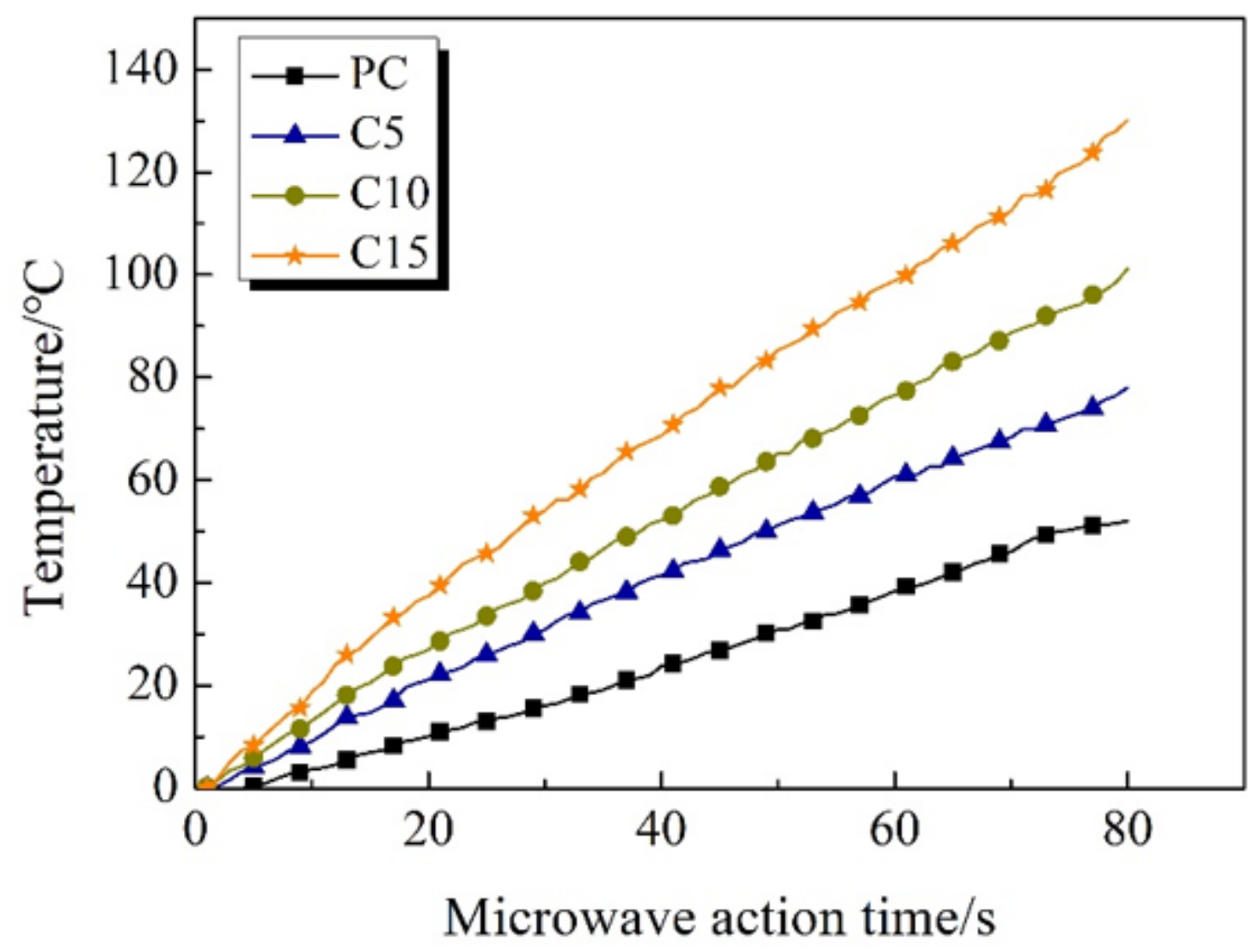

Figure 11

Real time temperature of graphite concrete 


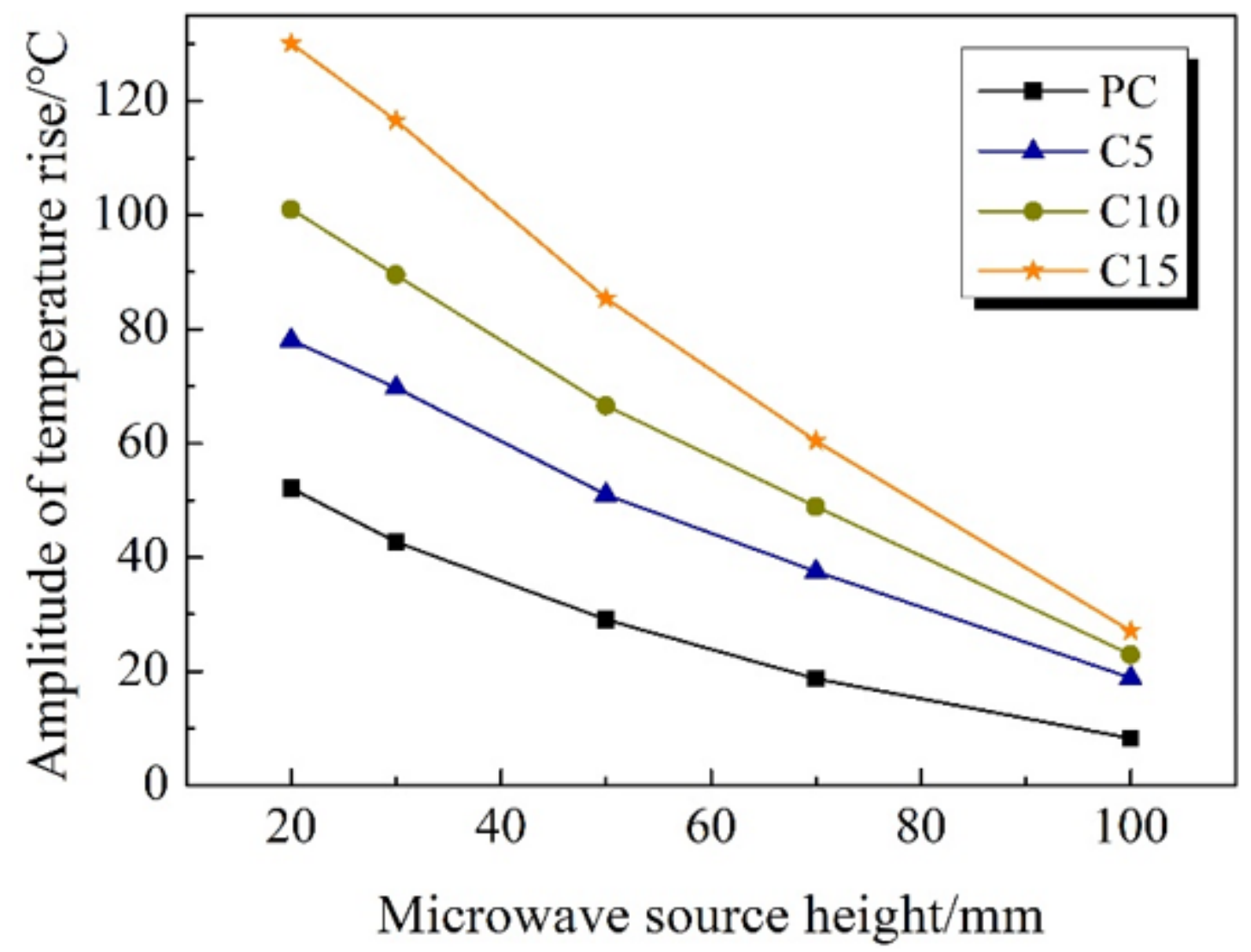

Figure 12

Amplitude of rising temperature of graphite concrete 


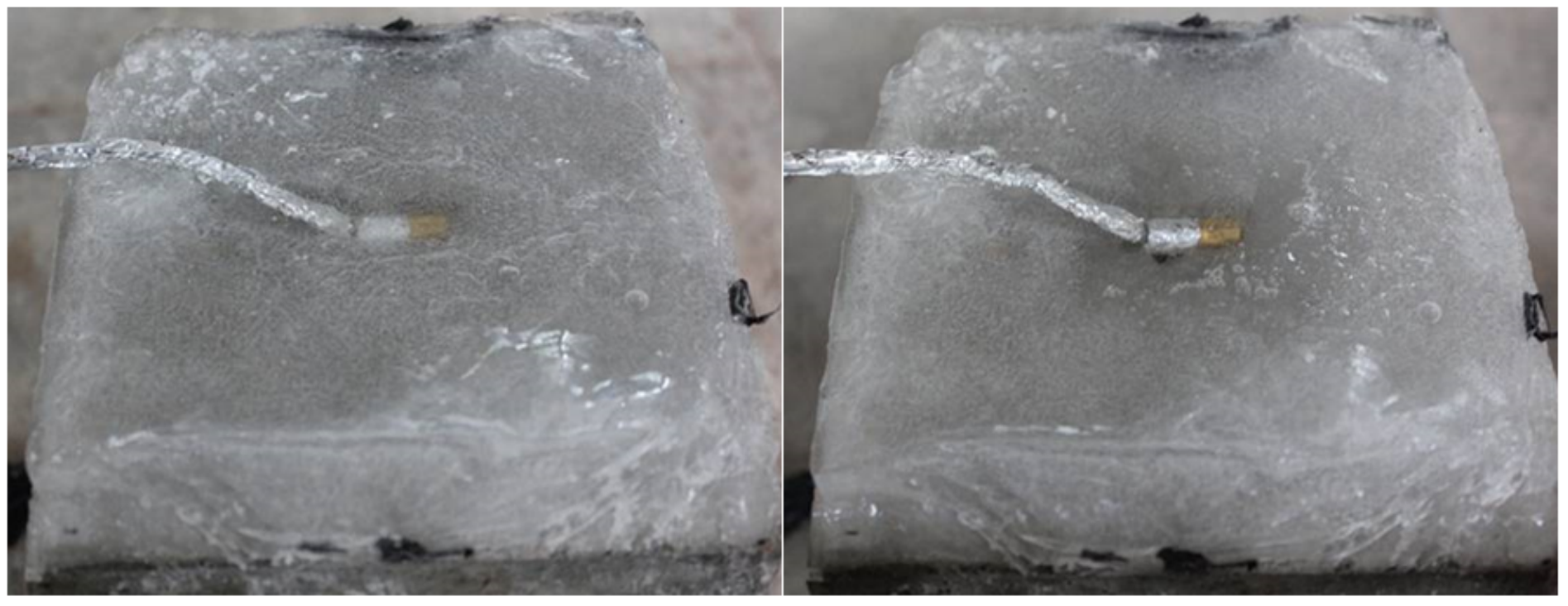

(a) $70 \mathrm{~s}$

(b) $90 \mathrm{~s}$

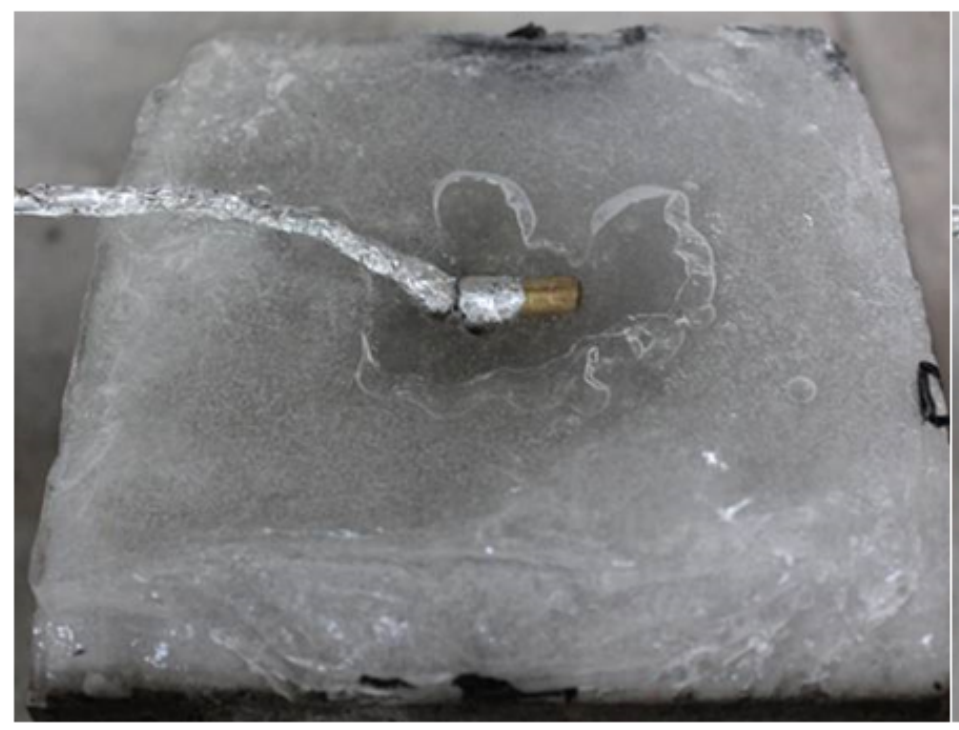

(c) $120 \mathrm{~s}$

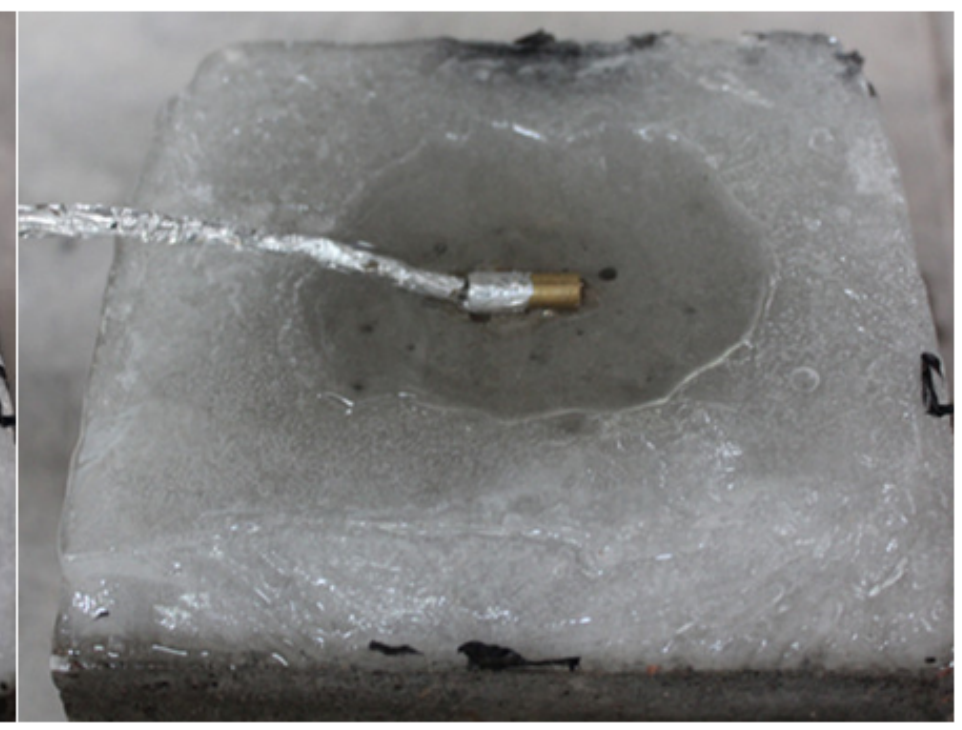

(d) $160 \mathrm{~s}$

Figure 13

Microwave deicing effect of SiC15 


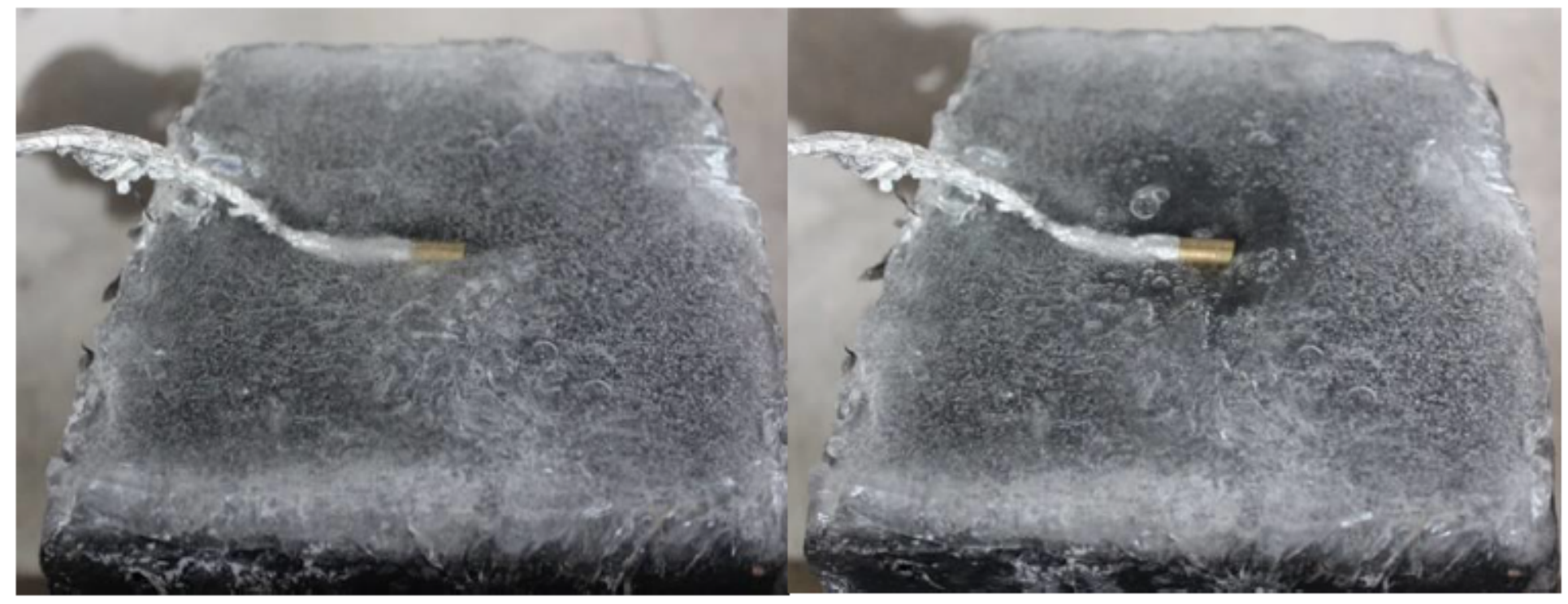

(a) $50 \mathrm{~s}$

(b) $70 \mathrm{~s}$

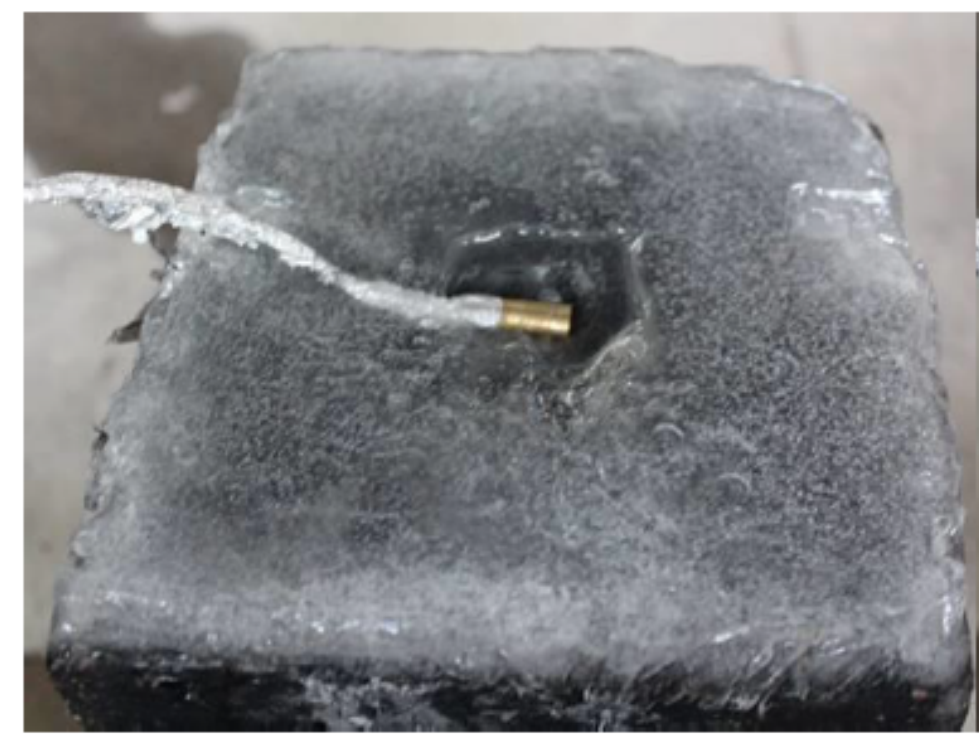

(c) $110 \mathrm{~s}$

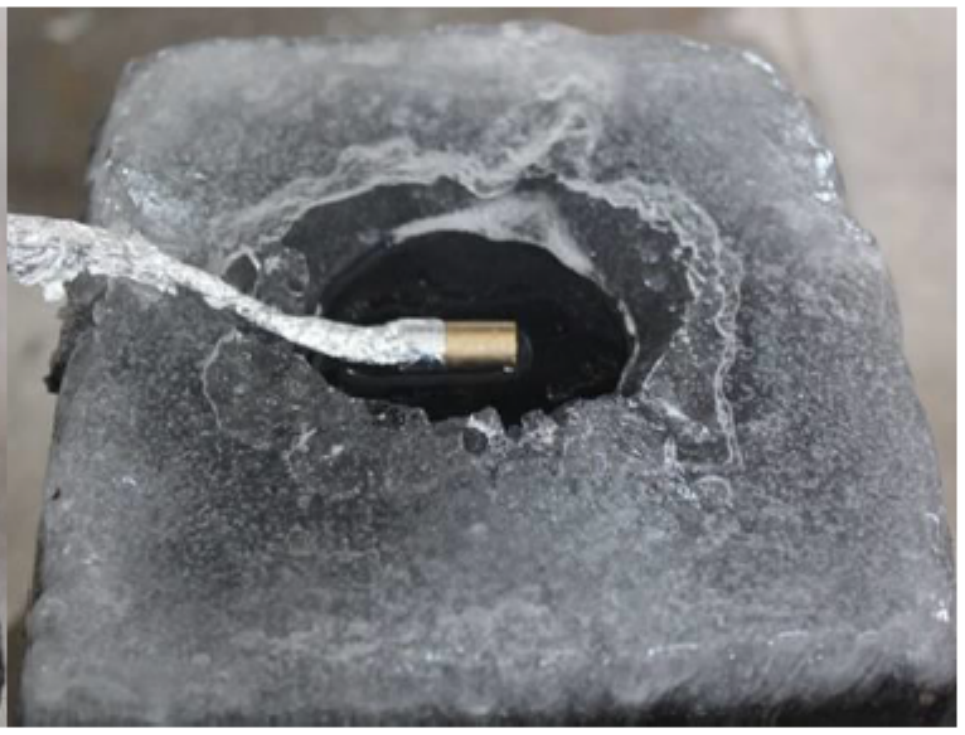

(d) $160 \mathrm{~s}$

Figure 14

Microwave deicing effect of Fe15 

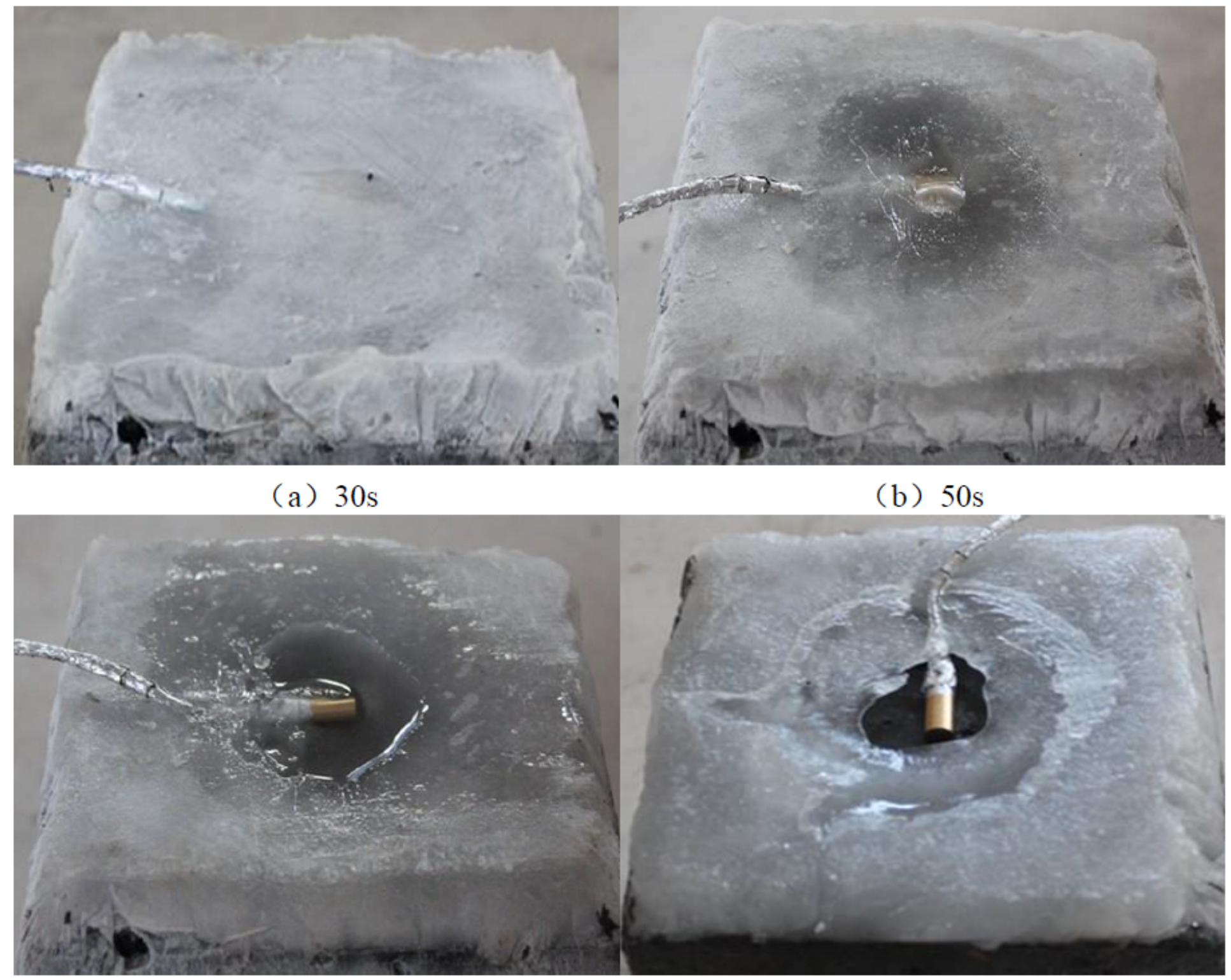

(b) $50 \mathrm{~s}$

(c) $90 \mathrm{~s}$

(d) $130 \mathrm{~s}$

Figure 15

Microwave deicing effect of C15 